\title{
KONTRIBUSI KELAS PERAHU DALAM MENGURANGI ANGKA PUTUS SEKOLAH DI PULAU SALEMO KECAMATAN LIUKANG TUPABBIRING UTARA KABUPATEN PANGKEP
}

\author{
Kasmawati Said $^{1}$, Supriadi Torro ${ }^{2}$ \\ ${ }^{1,2}$ Pendidikan Sosiologi-FIS UNM \\ kasmawatisaid7640@gmail.com ${ }^{1}$, supriaditorro@unm.ac.id ${ }^{2}$
}

\begin{abstract}
ABSTRAK
Penelitian ini bertujuan untuk mengetahui: (1) Model Pelaksanaan Kelas Perahu di Pulau Salemo Kecamatan Liukang Tupabbiring Utara Kabupaten Pangkep. (2) Kontribusi Kelas Perahu dalam mengurangi angka putus sekolah di Pulau Salemo Kecamatan Liukang Tupabbiring Utara Kabupaten Pangkep. Jenis penelitian ini adalah kualitatif dengan pendekatan deskriptif. Jumlah informan sebanyak 7 orang yang dipilih dengan teknik purposive sampling. Teknik pengumpulan data dengan observasi, wawancara, dan dokumentasi. Teknik analisis data menggunakan kondensasi data, model data, dan penarikan kesimpulan. Tahap pengabsahan data dengan member check. Adapun Hasil penelitian ini menunjukkan bahwa (1) memang terdapat layan Kelas Perahu yang sudah berlangsung sejak tahun 2016. Model pelakanaan Kelas Perahu di Pulau Salemo Kecamatan Liukang Tupabbiring Utara Kabupaten Pangkep yaitu model pembelajaran mandiri dengan menggunakan LKS, dan model pendampingan. (2) Kontribusi Kelas Perahu di Pulau Salemo Kecamatan Liukang Tupabbiring Utara Kabupaten Pangkep yaitu sebagai sarana belajar, meningkatkan hasil belajar siswa, menurunkan angka Drop Out (DO), Transformasi pendidikan, dan memberikan semangat.
\end{abstract}

Kata kunci: Kontribusi Kelas Perahu, Angka Putus Sekolah

\section{ABSTRACT}

This study ains to find out: 1) The model of boat class implementation in reducing drop out rates on salemo island, liukang tupabbiring north district, pangkep regency. 2) The contribution of the boat class in reducing drop out rates on salemo island, liukang tupabbiring north district, pangkep regency. This type of research is qualitative with a descriptive approach. The number of informants as many as 7 people were selected by purposive sampling technique. Data collection techniques with observation, interview, and documentation. Data analysis techniques use data condensation, data models, and drawing conclusions. Data validation stage with member check. As for the results of this study indicate that (1) indeed there is a boat class service that has been ongoing since 2016. The models of boat class implementation in reducing drop out rates on salemo island, liukang tupabbiring north district, pangkep regency namely the independent learning model using student worksheets, and a mentoring model. (2) The contribution of the boat class in reducing drop out rates on salemo island, liukang tupabbiring north district, pangkep regency namely as a means of learning, improving student learning outtcomes, reducing drop out rates, transforming education, and encouraging.

Keywords: Class Boat Contribution, Drop Out Rate

\section{PENDAHULUAN}

Pendidikan merupakan suatu hal yang sangat penting bagi kehidupan dimasa yang akan datang karena pendidikan yang baik dapat mengantarkan pada pekerjaan yang lebih baik sehingga mampu mengembangkan taraf hidupnya. Sejalan dengan itu menurut Undang-Undang Nomor 20 tahun 2003 tentang sistem pendidikan nasional bahwa:

"Pendidikan nasional berfungsi mengembangkan kemampuan dan membentuk watak serta peradaban bangsa yang bermartabat dalam rangka mencerdaskan kehidupan bangsa, bertujuan mengembangkan potensi peserta didik agar menjadi manusia yang beriman dan bertaqwa kepada Tuhan Yang Maha Esa, berakhlak 
mulia, sehat, berilmu, cakap, kreatif, mandiri, dan menjadi warga negara yang demokratis serta bertanggung jawab"(Irawati \& Susetyo, 2017).

Mengenai hak dan kewajiban warga negara telah diatur dalam Undang-Undang Nomor 20 tahun 2003 pasal 5 bahwa 1) setiap warga negara mempunyai hak yang sama untuk memperoleh pendidikan yang bermutu, 2) warga negara yang memiliki kelainan fisik, emosional, mental, intelektual, dan atau sosial berhak memperoleh pendidikan khusus, 3) warga negara di daerah terpencil atau terbelakang serta masyarakat adat yang terpencil berhak memperoleh pendidikan layanan khusus, 4) warga negara yang memiliki potensi kecerdasan dan bakat istimewa berhak memperoleh pendidikan khusus, dan 5) setiap warga negara berhak mendapat kesempatan meningkatkan pendidikan sepanjang hayat.

Seiring dengan itu Menteri Pendidikan dan Kebudayaan Kemendikbud juga mengungkapkan bahwa

"Negara indonesia memiliki jumlah siswa putus sekolah pada jenjang sekolah dasar sebanyak 39.213 siswa, pada jenjang sekolah menengah pertama sebanyak 38.702 siswa dan pada jenjang sekolah menengah keatas sebanyak 36.419 siswa. Sedangkan di provinsi sulawesi selatan memilki jumlah siswa putus sekolah pada jenjang sekolah dasar sebanyak 2.550 siswa, pada jenjang sekolah menengah pertama sebanyak 1.640 siswa dan pada jenjang sekolah menengah keatas sebanyak 1.384 siswa” (Gunawan, 2019).

Kabupaten Pangkep merupakan kepulauan yang terdiri dari darat, laut dan pegunungan terdapat 13 kecamatan. Dengan jumlah pulau sebanyak 115 yang tersebar dalam gugusan kepulauan (Malikuddin SW, 2018), (Qadaruddin, 2016). Bagi penduduk yang tinggal di wilayah kepulauan Kabupaten Pangkep umumnya memiliki mata pencaharian sebagai nelayan, untuk memenuhi kehidupan sehari-hari anak-anak ikut serta untuk membantu pekerjaan orang tua dilaut. Itulah yang menjadi salah satu penyebab banyaknya anak putus sekolah di wilayah kepulauan Kabupaten Pangkep. Anak yang tinggal di wilayah kepulauan juga memiliki hak yang sama dengan anak lainnya untuk mendapatkan pendidikan yang layak bagi kehidupannya. Seperti yang diatur oleh UUD 1945 pasal 31 yang mengatakan bahwa setiap warga negara berhak mendapat dan mengikutti pendidikan dasar dan pemerintah wajib membiayainya. Sehubungan data PISA yang dikeluarkan Kementrian Pendidikan dan Kebudayaan (Kemendikbud) jumlah angka putus sekolah di Indonesia masih sangat tinggi khusunya pada wilayah pedesaan maupun wilayah kepulauan seperti pulau yang terdapat di Kabupaten Pangkep.

Data jumlah siswa di Kecamatan Liukang Tupabbiring Utara pada tingkat SD sebanyak 1665 orang, siswa SMP sebanyak 634 orang. Dari jumlah tersebut sebanyak 102 siswa tingkat SD dan sebanyak 72 siswa tingkat SMP ikut melaut (Sari, 2019). Untuk mengurangi angka putus sekolah yang berada di wilayah kepulauan pangkep, Dinas Pendidikan Kabupaten Pangkep membuat inovasi kelas perahu di pulau Salemo Kecamatan Likang Tupabiring Utara, inovasi ini sangat membantu bagi anak yang melaut karena mereka membantu orangtua mencari nafkah sehingga mereka tetap bisa mengenyam pendidikan dan terdaftar sebagai siswa di sekolahnya masing-masing. Kelas Perahu adalah tempat belajar bagi siswa pada perahu yang digunakannya untuk melaut (Mansyur et al., 2019). Seperti yang dijelaskan oleh Rukmini bahwa:

"Pelayanan pendidikan melalui layanan "Kelas Perahu" memberikan kesempatan kepada semua anak untuk tetap bersekolah, baik yang terdaftar di sekolah reguler oleh pemerintah maupun yang dikelola masyarakat yang bersifat 
ramah anak. Kelas perahu ini sudah berlangsung selama kurang lebih 3 tahun” (Mansyur et al., 2019).

Sejak tahun 2016 kelompok rentang ini dijangkau melalui layanan kelas perahu yang lebih memberi kesempatan pada siswa yang melaut secara kontektual melalui guru yang berkomitmen untuk secara aktif memberikan layanan secara ikhlas agar siswa yang dari perahu ke perahu dari kegiatan sosialisasi kepada masyarakat kepulauan agar peserta didik yang selama ini putus sekolah karena melaut dapat kembali lagi bersekolah dengan ikut serta dalam layanan kelas perahu. Siswa yang putus sekolah tersebut umurnya berada pada usia 12 tahun atau pada tingkat kelas VI SD atau pada tingkat SMP. Usia inilah yang menjadi prioritas pelayanan kelas perahu, karena usia ini produktif membantu orang tuanya melaut dan orang tua siswa sangat berperan untuk mereka.

\section{METODE PENELITIAN}

Jenis penelitian ini adalah kualitatif deskriptif, teknik dalam menentukan informan menggunakan teknik Purposive Sampling dengan kriteria guru yang mengajar siswa di kelas perahu yang terdapat di Pulau Salemo Kecamatan Liukang Tupabiring Utara Kabupaten Pangkep, dan siswa yang belajar di kelas perahu yang terdapat di Pulau Salemo Kecamatan Liukang Tupabiring Utara Kabupaten Pangkep. Jumlah Informan sebanyak 2 orang guru yang mengajar di kelas perahu dan siswa yang belajar di Kelas Perahu sebanyak 5 orang. Teknik pengumpulan data dengan observasi, wawancara, dan dokumentasi. Teknik analisis data menggunakan kondensasi data, model data, dan penarikan kesimpulan (Huberman \& Miles, 2002). Tahap pengabsahan data dengan member check.

\section{HASIL PENELITIAN \& PEMBAHASAN}

\section{Model Pelaksanaan Kelas Perahu Di Pulau Salemo Kecamatan Liukang Tupabbiring Utara Kabupaten Pangkep.}

a) Model pembelajaran mandiri dengan menggunakan LKS

Berdasarkan hasil penelitian yang peneliti lakukan, Kelas Perahu merupakan sebuah layanan pendidikan yang diperuntukkan kepada siswa yang sedang melaut dengan menggunakan sistem pembelajaran mandiri dan dibantu oleh orangtua maupun keluarga lainnya dengan menggunakan Lembar Kerja Siswa (LKS) sebagai sumber belajar utama.

Ide atau konsep dalam penerapan kelas perahu merujuk pada psoses kegiatan belajar mengajar yang tidak dapat berjalan sepenuhnya dengan metode tatap muka, sehingga harus menyusun LK sebagai penggantinya yang disertai dengan petunjuk cara belajar secara mandiri dan sesuai dengan kurikulum. Selain petunjuk cara belajar secara mandiri, guru dapat memberikan bimbingan kepada siswa Kelas Perahu dan memberikan konsultasi dengan orangatau atau pendamping (orang yang bertanggung jawab selama melaut) dalam mendukung belajar siswa di atas perahu atau kapal.

Sedangkan penyusunan Lembar Kerja disusun oleh guru dengan mengacu pada materi berdasarkan buku teks dan sumber belajar lainnya sesuai dengan RPP yang dibuat oleh guru. Kemudian Lembar kerja yang telah dikerjakan oleh siswa yang melaut akan dikumpulkan kepada gurunya, selanjutnya guru akan mengevaluasi hasil lembar kerja siswa dan bagi siswa yang nilainya lengkap akan diikutkan untuk mengikuti ujian kenaikan kelas maupun ujian kelulusan sedangkan siswa yang nilainya tidak lengkap tidak diikutsertakan mengikuti ujian. 
b) Model pendampingan,

Adapun model pendampingan juga diterapkan oleh guru dan orangtua siswa juga dianggap efektif karena sebelum siswa berangkat kelaut akan diberikan arahan oleh guru dan pada saat siswa belajar diatas perahu mereka akan diawasi oleh orangtuanya. Model pendampingan dilakukan oleh guru sebelum siswa berangkat pergi melaut dengan cara guru menentukan topik yang dapat dipelajari oleh siswa,memberikan penjelasan mengenai materi yang akan diberikan ke siswa dan menjelaskan petunjuk dalam mengerjakan lembar kerja agar siswa tersebut tidak merasa bingung jika belajar tanpa didampingi oleh gurunya, sedangkan pendampingan yang dilakukan oleh orangtua siswa yaitu dengan cara mengawasi putra/putri mereka saat sedang belajar diatas perahu.

\section{Kontribusi Kelas Perahu Dalam Mengurangi Angka Putus Sekolah Di Pulau Salemo} Kecamatan Liukang Tupabbiring Utara Kabupaten Pangkep.

a) Sebagai sarana belajar,

Pendidikan bagi anak yang tinggal di daerah kepulauan pada umumnya memiliki masalah yang sama yaitu tingkat pendidikan yang rendah, kehidupan sosial ekonomi yang tidak memadai. Padahal pendidikan merupakan salah satu kunci utama untuk menciptakan dan membentuk kualitas manusia yang unggul serta memiliki daya saing yang kuat. Seperti yang diungkapkan oleh bahwa "Pada prinsipnya pendidikan harus dinikmati oleh semua warga negara Indonesia"(Itasari, 2020).

Namun, tidak semua warga negara mempunyai kesempatan yanng sama dalam mengenyam pendidikan sewajarnya. Mengikuti proses pembelajaran di sekolah menjadi persoalan tersendiri bagi anak-anak yang bertumbuh dan tinggal di daerah kepulauan atau anak-anak yang terpaksa mengikuti orangtuanya melaut dari pagi, siang, malam bahkan subuh sehingga mereka putus sekolah demi mencari nafkah. Berdasarkan hasil penelitian yang dilakukan peneliti menarik kesimpulan bahwa Anak-anak nelayan di Pulau Salemo umumnya menempuh pendidikan formal. Sekolah-sekolah formal dijadikan sebagai sarana pendidikan yang utama untuk mendapatkan ilmu pengetahuan. Namun bagi orangtua tidak ada pilihan lain sehingga anak dijadikan sebagai tumpuan harapan untuk membantu mencari nafkah dalam memenuhi kebutuhan rumah tangga, di sisi lain anak perlu waktu untuk menyelesaikan tugas-tugas belajar yang diberikan oleh guru di sekolah. Untuk itu Dinas Pendidikan Kabupaten Pangkep menghadirkan layanan kelas perahu.

"Kelas Perahu" telah memberikan kontribusi dengan baik. Setiap siswa yang harus meninggalkan pelajarannya di sekolah hanya untuk membantu orangtua melaut akan diberikan kesempatan oleh pihak sekolah agar siswa tersebut tetap bisa belajar meskipun harus di luar kelas seperti perahu,kapal dan bagan sehingga mereka tetap bisa melanjutkan pendidikannya dan tidak putus sekolah.

b) Meningkatkan hasil belajar siswa

Hasil belajar pada hakekatnya adalah perubahan tingkah laku sebagai hasil dari belajar yang wujudnya berupa kemampuan kognitif, afektif, dan psikomotorik yang disebabkan oleh pengalaman (Zakiah, 2020). Setelah proses belajar selesai maka siswa akan memperoleh suatu hasil belajar. Hasil belajar inilah yang akan digunakan untuk mengetahui sejauh mana siswa bisa memahami materi yang dipelajarinya. Hasil belajar siswa yang ikut belajar di kelas perahu setiap tahunnya mengalami peningkatan. Hal ini ditandai dengan nilai tugas siswa tidak ada lagi yang tidak terisi sehingga siswa tersebut bisa diikutsertakan mengikuti ujian nasional maupun ujian kenaikan kelas. 
c) Menurunkan angka drop out (DO)

Penduduk yang mendiami Pulau Salemo umumnya memilik mata pencaharian nelayan (Ibrahim, 2018). Orangtua saat melaut juga mengikut sertakan anak-anaknya demi memenuhi kebutuhan hidup sehari-hari. Keterlibatan anak yang melaut inilah yang membuat mereka harus meninggalkan pembelajarannya di sekolah sehingga lambat laun membuat anak usia sekolah merasa malu atau enggan kembali masuk sekolah. Selanjutnya karena tidak pernah datang ke sekolah lagi, anak-anak ini mengakibatkan tingginya angka putus sekolah pada jenjang SD maupun SMP.

Berdasarkan data yang peneliti peroleh dari kantor Desa Matiro Bombang Kecamatan Liukang Tupabbiring Utara pada tahun 2016 jumlah siswa putus sekolah sebanyak 28 siswa diantaranya 13 siswa tingkat SD, 9 siswa tingkat SMP dan 6 siswa tingkat SMA, pada tahun 2017 siswa yang putus sekolah sebanyak 18 siswa diantaranya 8 siswa tingkat SD, 6 siswa tingkat SMP dan 4 siswa tingkat SMA, Sedangkan pada tahun 2018 siswa yang putus sekolah sebanyak 10 siswa diantaranya 5 siswa tingkat SD, 4 siswa tingkat SMP dan 1 siswa tingkat SMA. Hal ini menunjukkan bahwa setelah munculnya layanan inovasi kelas perahu di tahun 2016, anak yang putus sekolah sudah mulai menurun dari tahun ke tahunnya.

d) Transformasi pendidikan

Munculnya layanan inovasi Kelas perahu dengan cara memfasilitasi layanan pendidikan bagi anak pulau menciptakan sebuah transformasi pendidikan. Pendidikan di sekolah dasar yang biasanya diadakan di ruang kelas saja, kini telah diubah. Belajar di sebuah perahu, di tengah lautan sembari membantu orangtua yang dapat dilakukan kapan saja, pagi, siang, malam, ataupun subuh hari.

Kelas perahu melakukan transformasi pendidikan khususnya di Sekolah Dasar 4 Pulau Salemo dan SMP-SMA PGRI Pulau Salemo Kecamatan Liukang Tupabbiring Utara Kabupaten Pangkep namun tetap bertujuan yang sama yaitu menyediakan pendidikan dasar bagi anak pulau di Kabupaten Pangkep.

Dengan hadirnya layanan "Kelas Perahu" telah memberikan kontribusi yang baik. Anak-anak dapat belajar di atas perahu dan di ruangan kelas. Guru dengan pro-aktif membantu siswa dengan memberikan tugas di Lembar Kerja Siswa dan mengoreksi juga menjelaskan materi setelah anak-anak tersebut kembali ke darat. Jika anak-anak tersebut tidak melaut mereka diperbolehkan untuk datang kesekolah bergabung dengan temannya di ruangan kelas seperti biasa untuk mengikuti pelajaran. Namun guru-guru khususnya di Pulau Salemo sangat berperan penting untuk memberikan kemudahan belajar bagi anakanak pulau, pelayanan yang cepat, mudah dan tidak berbayar.

e) Memberikan semangat

Kelas Perahu juga dianggap aktif dalam memberikan dorongan dan semangat akan pentingnya pendidikan, baik itu kepada siswa anak nelayan hingga orangtua siswa yang berada di daerah kepulauan tersebut. Sehingga anak-anak nelayan yang lebih banyak menghabiskan waktunya di laut demi mencari nafkah memiliki motivasi yang lebih guna melanjutkan pendidikan kejenjang yang lebih tinggi. Selain itu masyarakat dan khusunya orangtua siswa jugaa diharapkan memiliki andil yang lebih dalam mendukung pendidikan yang ditempuh oleh anaknya, sehingga pendidikan dasar tidak hanya dianggap sebagai tempat yang hanya memperoleh kemampuan membaca, menghitung dan menulis, pendidikan tidak hanya cukup jika menguasai kemampuan tersebut di tingkat dasar. 
Lebih daripada itu, pendidikan dasar mesti dijadikan sebagai batu loncatan untuk memahami bidang ilmu yang lain, sehingga pada suatu waktu siswa yang anak nelayan tersebut dapat melanjutkan pendidikan ke jenjang yang lebih tinggi hingga dapat berguna dan bisa memajukan daerahnya.

\section{PENUTUP}

Model pembelajaran kelas perahu dalam mengurangi angka putus sekolah di Pulau Salemo Kecamatan Liukang Tupabbiring Utara Kabupaten Pangkep adalah: a) model pembelajaran mandiri dengan menggunakan LKS, b) model pendampingan. Kontribusi kelas perahu dalam mengurangi angka putus sekolah di Pulau Salemo Kecamatan Liukang Tupabbiring Utara Kabupaten Pangkep adalah: a) sebagai sarana belajar, b) meningkatkan hasil belajar siswa, c) menurunkan angka Drop Out (DO), d) transformasi pendidikan, e) memberikan semangat. Hasil penelitian mengenai kontribusi kelas perahu dalam mengurangi angka putus sekolah di Pulau Salemo Kecamatan Liukang Tupabbiring Utara Kabupaten Pangkep menunjukkan bahwa pentingnya pendidikan khususnya bagi anak yang berada di wilayah kepulauan sehingga diharapkan dapat memberikan kebijakan yang disesuaikan dengan kondisi masyarakat agar kelas perahu dapat berperan dalam meningkatkan angka partisipasi pendidikan dan mengurangi angka putus sekolah.

\section{DAFTAR PUSTAKA}

GUNAWAN, H. (2019). FAKTOR PENYEBAB DAN DAMPAK ANAK PUTUS SEKOLAH (Studi Kasus pada Anak Putus Sekolah Tingkat SLTP dan SLTA di Kecamatan Air HitamKabupaten Lampung Barat).

Huberman, M., \& Miles, M. B. (2002). The qualitative researcher's companion. Sage. Ibrahim, I. (2018). SISTEM KEPERCAYAAN SEBAGAI BASIS-STRUKTUR SOSIAL MASYARAKAT NELAYAN LIUKANG TUPABBIRING DI KABUPATEN PANGKEP. Al-Qalam, 16(2), 141-152.

Irawati, E., \& Susetyo, W. (2017). Implementasi Undang-Undang Nomor 20 Tahun 2003 Tentang Sistem Pendidikan Nasional Di Blitar. Jurnal Supremasi, 7(1), 3.

Itasari, E. R. (2020). Hak Pendidikan di Wilayah Perbatasan Dalam Kerangka Konstitusi Republik Indonesia. Jurnal Media Komunikasi Pendidikan Pancasila Dan Kewarganegaraan, 2(1), 79-100.

Malikuddin SW, M. S. W. (2018). Konsep Pembangunan Minawisata pada Desa Mattiro Baji Kecamatan Liukang Tupabbiring Utara Kabupaten Pangkajene dan Kepulauan. Universitas Islam Negeri Alauddin Makassar.

Mansyur, K., Umrah, M., \& Rifal, M. (2019). Budaya Pendidikan Anak Pesisir di Wilayah Kepulauan Spermonde. JURNAL PEMIKIRAN DAN PENGEMBANGAN PEMBELAJARAN, 1(2), 1-14.

Qadaruddin, M. (2016). Fenomenologi Akulturasi Budaya dan Agama. Lumbung Informasi Pendidikan.

Sari, D. (2019). Analisis Inovasi Pelayanan Publik" Kelas Perahu" Kabupaten Pangkajene dan Kepulauan. SAP (Susunan Artikel Pendidikan), 3(3).

Zakiah, L. (2020). Hubungan Kecerdasan Sosial dan Hasil Belajar Siswa Kelas IV Sekolah Dasar. PARAMETER: Jurnal Pendidikan Universitas Negeri Jakarta, 32(1), 30-52. 